\title{
Morphology/tensile Performance Relationship for LLDPE/PP Double Gated Injected Blends
}

\author{
Caren Rosales ${ }^{1}$, Diego Brendstrup ${ }^{2}$, Celina Bernal ${ }^{2}$, Valeria Pettarin ${ }^{1, *}$ \\ ${ }^{1}$ Polymer Science and Engineering Group, Institute of Materials Science and Technology (INTEMA), University of Mar del \\ Plata - CONICET, Av. Colon 10850, 7600 Mar del Plata, Argentina \\ ${ }^{2}$ ITPN, UBA/CONICET, Buenos Aires, Argentina
}

*Corresponding author: E-mail: pettarin@fi.mdp.edu.ar

DOI: 10.5185/amlett.2020.021472

Due to the large volume consumption of plastics, the treatment of the resulting solid waste is becoming a major concern. Polyethylene and polypropylene are two of the most abundant polymers in waste. Recycling them as a blend is an attractive way to reduce the impact of plastic wastes. This work is focused on the relationship between material morphology and tensile behavior, both under static and dynamic loading conditions, of PP/LLDPE blends with varying relative content. Blends present a biphasic morphology with distinctive characteristics that depends on blend composition. Their tensile properties are significantly affected by composition and corresponding morphology: mechanical behavior varied from ductile to brittle under both quasi-static and dynamic loading conditions. The blend with the better and most reliable behavior was found to be the one with $75 \%$ of LLDPE, and in a next work it will be used to obtain a ternary composite reinforced with recycled rubber particles obtained from scrap tires.

\section{Introduction}

Global warming awareness, environmental and waste issues management are some of the reasons for the increasing worry about waste recycling. Due to the large volume consumption of plastics, the treatment of the resulting solid waste is becoming a major concern. Polyethylene (PE) and polypropylene (PP) constitute a significant part of the solid waste, i.e. they are two of the most abundant polymers in waste. Their separation in common waste recovery operations is very difficult. Moreover, complete separation is sometimes impossible. Recycling them as a blend, on the other hand, provides a possible direction to reduce the impact of plastic wastes [1-5].

Several authors have studied PE/PP blends, including blends of PP with HDPE, LDPE and LLDPE [6-9]. These components are immiscible and incompatible, and due to their poor interfacial adhesion, their applications are limited. Morphology and crystallization mechanisms have been studied, finding that these blends showed two different endothermic peaks by DSC, droplets of minority component in a matrix of another constituent by SEM and characteristics crystallographic peaks by DRX.

Mechanical properties of these blends not only depend on the component's characteristics but also on the blend composition and processing method, i.e mixing, extrusion, injection molding, compression molding and their processing parameters (such as temperature, pressure and speed). The composition ratio between PE and PP will give different mechanical properties to the final blend due to the contribution of each phase. On one hand, largest elongation and toughness provided by PE phase, and on the other hand, greatest crystallinity and stiffness provided by PP phase, which are desired simultaneously [6-10].

The aforementioned is completely related to each other since the processing conditions regulates the final blend morphology, and this in turn controls mechanical properties. Variation of morphology makes it possible to obtain diverse mechanical properties for similar blends (similar composition ratio, compatibilization, processing parameters).

The compatibilization process between phases is an important aspect of these blends. There are several works in literature that focus on the use of different amounts of thermoplastics or elastomeric copolymers for compatibilization. It was found that the incorporation of a compatibilizer agent had an good influence on the blend's mechanical properties. Tensile parameters were found to be better due to the improvement of the copolymer in interfacial adhesion and load transfer between phases. In addition, it was found that elastomeric copolymers can also improve impact strength $[\mathbf{1 , 3}, \mathbf{1 1 - 1 3}]$.

Due to the increasing interest in these blends, it is therefore essential to understand the processing/ morphology/performance relationship of $\mathrm{PP} / \mathrm{PE}$ blends with the aim to improve them. Here relies the novelty of our work. Our proposal is to select one blend composition with a good thermal/mechanical performance, to be used as a matrix of a ternary compound, to which recycled elastomeric particles will be added in order to get an engineering composite. Following this idea, this work is focused on the relationship between material morphology and tensile behavior, both under static and dynamic loading conditions, of PP/LLDPE blends with varying relative content. 


\section{Advanced Materials Letters www. vbripress.com/aml}

\section{Experimental}

\section{Materials and blends preparation}

Commercial linear low density polyethylene (LLDPE) Dowlex IP20 (MI = $20 \mathrm{gr} / 10 \mathrm{~min}\left(190^{\circ} \mathrm{C} / 2.16 \mathrm{~kg}\right)$ from Dow Argentina, and polypropylene (PP) 1100SC (MI = $25 \mathrm{gr} / 10 \mathrm{~min}\left(230^{\circ} \mathrm{C} / 2.16 \mathrm{~kg}\right)$ from Cuyolen Petroquìmica Cuyo, Argentina, were used in this work. Block copolymer 2630PC $\left(\mathrm{MI}=20 \mathrm{gr} / 10 \mathrm{~min}\left(190^{\circ} \mathrm{C} / 2.16 \mathrm{~kg}\right)\right.$ from Cuyolen, was used as compatibilizer.

PP and PE pellets were manually premixed in a container and then mixed in a twin screw extruder, with temperatures from hooper to die equal to 150,170 and $200^{\circ} \mathrm{C}$ and a rotational speed of $80 \mathrm{rpm}$. Obtained blends and neat homopolymers were then processed using a Multiplast 10T molding machine equipped with a double gated injection mold. Plaques of $60 \mathrm{~mm}$ width, $100 \mathrm{~mm}$ length and $2 \mathrm{~mm}$ thick were obtained. Processing parameters were set as: injection temperature $=210^{\circ} \mathrm{C}$; injection speed $=45 \mathrm{~mm} / \mathrm{s}$; injection pressure $=22 \mathrm{MPa}$; injection time $=3 \mathrm{~s}$; packing pressure $=21 \mathrm{MPa}$; packing time $=15 \mathrm{~s} ;$ cooling time $=20 \mathrm{~s} ;$ mold temperature $=$ $20^{\circ} \mathrm{C}$. In order to assess the influence of the compatibilizer on homopolymer properties, plaques of homopolymers with $5 \mathrm{wt} . \%$ of compatibilizer were also processed. Studied materials are detailed in Table $\mathbf{1}$.

Table 1. Composition and nomenclature of the samples analyzed.

\begin{tabular}{l|c|c|c}
\hline Sample & PE $(\mathbf{w t} \%)$ & PP $(\mathbf{w t} \%)$ & Copolymer $\mathbf{( w t \% )}$ \\
\hline PE & 100 & 0 & 0 \\
\hline PE-cop & 95 & 0 & 5 \\
\hline 7525 & 72.5 & 22.5 & 5 \\
\hline 5050 & 47.5 & 47.5 & 5 \\
\hline 2575 & 22.5 & 75.2 & 5 \\
\hline PP-cop & 0 & 95 & 5 \\
\hline PP & 0 & 100 & 0 \\
\hline
\end{tabular}

\section{Morphology and microstructure}

To observe the obtained microstructure some samples were notched, frozen in liquid nitrogen and cryo-fractured. Micrographs of the cryo-fractured surfaces were taken with a Jeol JSM 6460 scanning electron microscope (SEM), after they had been coated by a thin layer of gold.

$\mathrm{X}$-ray diffraction (XRD) was performed with a Phillips X'PERT MPD diffractometer in reflection mode $(\mathrm{Cu} \mathrm{K}$ " radiation $\$=1.5418 \AA$, generator voltage $40 \mathrm{kV}$, current $40 \mathrm{~mA}$, sample to detector distance $240 \mathrm{~mm}$ ) to observe the PP structure in the skin and the core of the injected pieces.

Differential Scanning Calorimetry (DSC) analysis was carried out with a Pyris 1 Perkin Elmer under nitrogen atmosphere. Samples were heated from 50 to $200^{\circ} \mathrm{C}$ at $10^{\circ} \mathrm{C} / \mathrm{min}$ and then crystallinity was determined. Parameters for melting of PE and PP compounds were obtained using custom software. The detailed methodology has been previously reported in Canedo et al. [14] and widely tested in the literature [15-18]. The percentage crystallinities of LDPE and PP in blends were calculated using the relationship:

$$
\% \text { Crystallinity }=\left(\Delta H_{f}^{o b s} / \Delta H_{f}^{0}\right) 100 . \Phi
$$

where $\Delta H_{f}^{o b s}$ is the observed heat of fusion, $\Delta H_{f}^{0}$ is the heat of fusion for $100 \%$ crystalline LDPE $(293 \mathrm{~J} / \mathrm{g}$ ) or PP $(207 \mathrm{~J} / \mathrm{g})$, and $\Phi$ is the weight fraction of constituent.

\section{Mechanical testing}

Obtained materials were tested in uniaxial tension under both quasi static and dynamic loading conditions. Dogbone specimens were cut from molded plaques following melt flow direction (MD).

Quasi-static tensile tests were performed in an Instron universal testing machine (Model 5982), in accordance with ASTM D638 standard recommendations. Data for yield strength, ultimate tensile strength and Young`s modulus were obtained from tests carried out at a crosshead speed of $5 \mathrm{~mm} / \mathrm{min}$.

Tensile impact tests were also performed on dumbbell specimens by following ISO 8256 standard recommendations at $1 \mathrm{~m} / \mathrm{s}$ in an Amsler pendulum (19.6 J).

Post morten fracture surfaces were observed by SEM, after they had been coated by a thin layer of gold.

\section{Results and discussion}

\section{Morphology and microstructure}

SEM micrographs of cryo-fractured surface of neat polymers and blends are presented in Fig. 1. As PP has a limited compatibility with LLDPE, small voids formed on the fracture surface because of the pullout of LLDPE droplets from the matrix during cryofracture [19]. Then, morphology varies from the typical particulate morphology of minority phase for 2575 and 7525 blends to a co-continuous like phase for 5050 blend, similarly to what was previously observed by other authors $[\mathbf{3 , 2 0 - 2 2}]$. In the case of 7525, PP particles of less than $1 \mu \mathrm{m}$ diameter in a LLDPE matrix can be easily observed, while 2575 presents polyethylene droplets of $200 \mathrm{~nm}$ dispersed in a PP matrix.

As previously said, processing parameters greatly influence morphology of processed materials. High extrusion screw speed induces smaller size of the dispersed component, i.e. a finer morphology. However, this refinement in morphology has a limit at which no further second phase size reduction is obtained. Other authors obtained particle size similar to ours by using a screw speed of $100 \mathrm{rpm}[\mathbf{2 3}]$ while screw rotation speeds of $60 \mathrm{rpm}$ induces bigger second phase sizes $[\mathbf{3 , 6}]$. It seems that the used screw speed of $80 \mathrm{rpm}$ was enough to attain a good refinement of second phase.

Regarding 5050, inside the co-continuous structure, a morphology that recalls a "salami" structure is observed, with big particles of one phase containing small particles of the other constituent, immersed in a matrix of the same constituent. This type of morphology has been largely described for high impact polystyrene (HIPS) [24], and also described it as occlusions. In all blends, some tendon 


\section{Advanced Materials Letters www. vbripress.com/aml}

like strings are observed holding particles into matrix holes in higher magnification SEM micrographs. These strings are evidence of interfacial adhesion between phases [19] maybe because of a certain amount of miscibility due to the presence of the compatibilizer. Regarding the morphology near the weld line, differences were observed between 7525 and 2575 blends (Fig.1b). Elongated particles are present probably due to the elongation stresses induced by flow during mold filling.

(a)
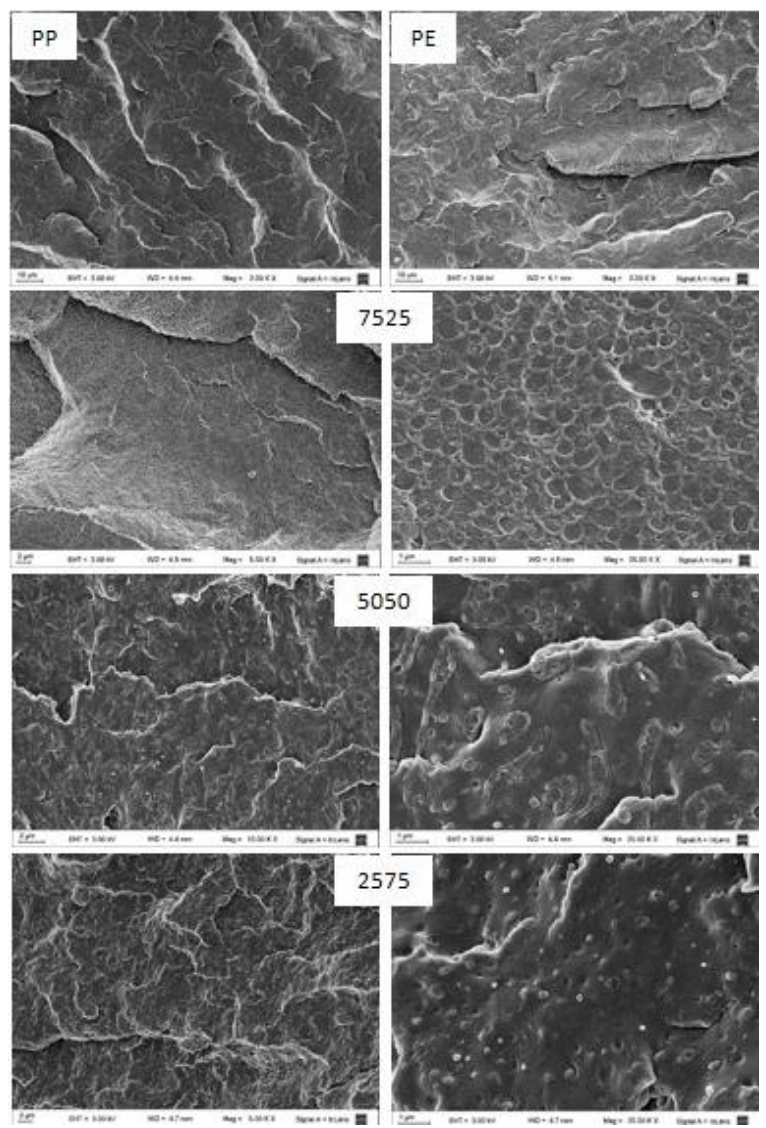

(b)

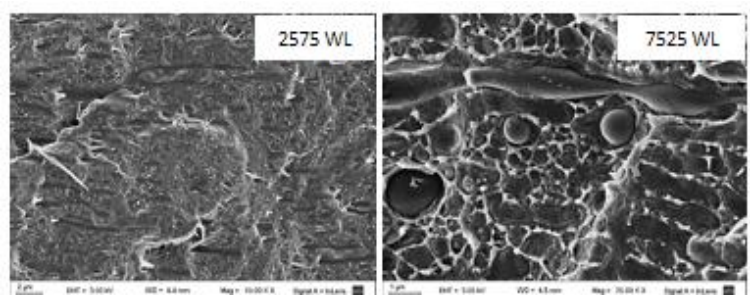

Fig. 1. SEM micrographs of cryo-fractured surface for all blends, (a) away from weld line, (b) at the weld line zone.

The effect of the blending ratio on thermal behavior of injected samples is shown in Fig. 2a, along with crystalline melting temperatures. Pure LLDPE and PP exhibit one main melting peak at 123.8 and $168{ }^{\circ} \mathrm{C}$, respectively. Two separated endothermic peaks are observed in all LLDPE/PP blends, which is an additional indication of incompatibility between both polymers. The intensities of melting peaks are directly related to the respective amount of PP and LLDPE phases. A small shoulder appears at the lower temperature region in LLDPE. In addition, the melting temperature of PP changes with blending. The presence of PP does not influence the melting temperature $\left(\mathrm{T}_{\mathrm{m}}\right)$ of LLDPE, but the addition of LLDPE causes the shift to lower values of the melting temperature of PP, this shift varying between 0.9 and $2.8^{\circ} \mathrm{C}$. Similar observation was reported in the literature $[\mathbf{1 , 2 , 1 3}]$ and considered as an indication of partially miscibility between LLDPE and PP, especially in LLDPE rich blends.

(a)

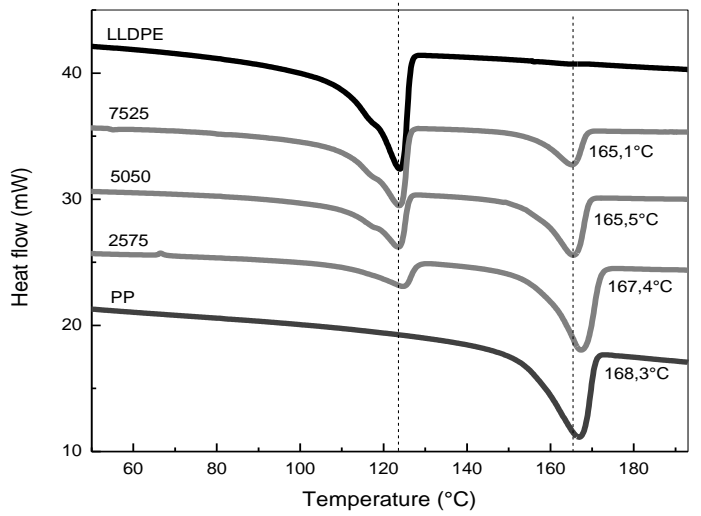

(b)

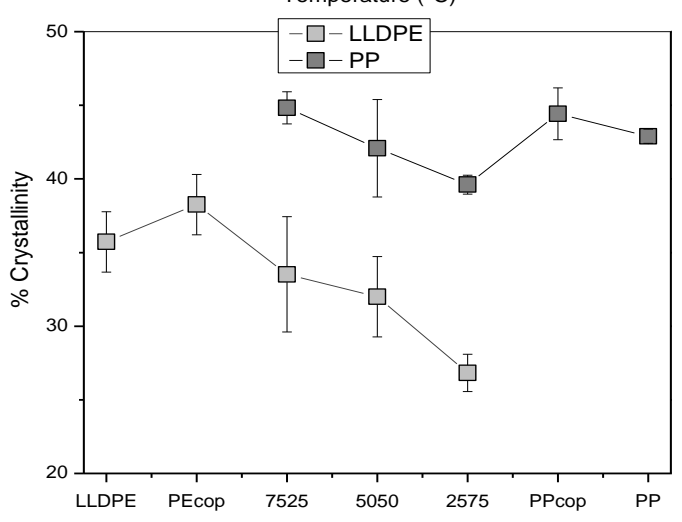

Fig. 2. DSC results, (a) representative heating curves, (b) variation of relative percentage crystallinity.

Mechanical properties of blends may be considerably affected by the degree of crystallinity and the type of crystals present $[\mathbf{2 5}]$. The influence of the blending ratio on the crystallinity of each component can be observed in Fig. 2b. It is seen that the crystallinity of PP and LLDPE is not affected by presence of the compatibilizier (PECOP and PPCOP). Moreover, the crystallinity of PP remains almost constant for varying LLDPE content. The crystallinity of LLDPE, in contrast, decreases with the incorporation of the other constituent. Similar results have been previously reports by others [25]. This can be due to the fact that upon cooling, PP crystalizes first (at approximately $130^{\circ} \mathrm{C}$ ), within a $\mathrm{PE}$ that is in the melting state, i.e. it barely obstructs PP spherulites growth. On the other side, LLDPE crystallizes in between already formed PP spherulites, i.e. in a complicated path, that being the reason of its lowering crystallinity $[2,6]$. Unlike compression molding, where polymers cystalize from a quiescent melt and the morphology is spherulitic, in injection molding, polymers crystalize from a melt that 


\section{Advanced Materials Letters www. vbripress.com/aml}

has been exposed to flow, shear and temperature variation. As a result, the crystallinity of our blends processed by injection molding are higher than that of blends processed by compression molding [6]. Moreover, melt temperature and mold temperature affect the temperature gradient and shear rate in injection molding, two variables which are expected to influence crystallization [26]. Temperature gradient is also affected by part thickness and geometry. Therefore, it is not always possible to make a direct comparison with others results. However, the same trend was found in literature for similar blends $[\mathbf{1 2 , 2 2}]$.

X-ray diffractograms of all samples (Fig. 3) exhibit the characteristic diffraction peaks of the monoclinic $\alpha$ phase of PP at scattering angles $2 \theta$ of 14.2 (110), 17.1 (040), 18.6 (130), as well as characteristic crystalline peaks of orthorhombic crystals of LLDPE at 21.4 (110) and 23.7 (200) $[\mathbf{2 7 , 2 8}$. This clearly suggests that the characteristic crystals of PP and LLDPE are retained, namely, the intrinsic crystal structure of both $\mathrm{PE}$ and $\mathrm{PP}$ are not influenced by the presence of the other constituent [29]. Moreover, surface and core reflections are similar, indicating similar crystal morphology development all over the injected pieces.

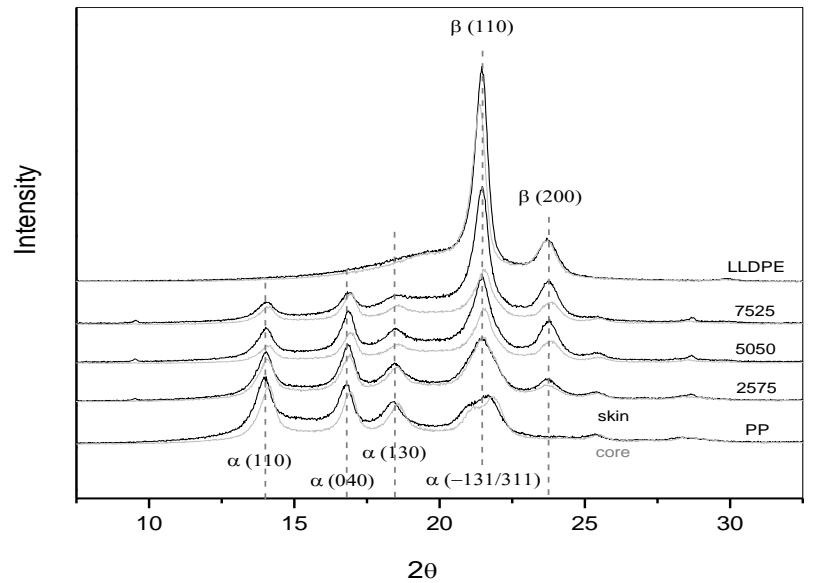

Fig. 3. X-ray diffractograms of investigated blends.

\section{Tensile performance}

All samples exhibited typical ductile behavior under quasi-static tensile loading, with a maximum in the stressstrain curve related to the initiation of necking. Values of yield strength and Young`s Modulus, as determined from tensile curves, are shown in Fig. 4a as a function of composition. Tensile parameters are found to be very dependent on the blend composition, increasing with increasing PP content, due to the higher stiffness and crystallinity of this polymer [5]. It is also observed that yield strength and Young's Modulus values vary following the rule of mixtures $[\mathbf{5 , 6 , 1 2}]$. Elongation at break is plotted versus composition in Fig. $\mathbf{4 b}$. The addition of the compatibilizer does not affect the elongation at break of pure homopolymers. However, the ductility of blends are lower than that of homopolymers, i.e. blends fail much more quickly than pure PP and LLDPE. The necking during stretching of a polymer is, in fact, an expression of the yield behavior of the material mainly attributable to the morphological structure and the nature of the interface between the two phases [22]. The observed negative deviation from a rule of mixtures demonstrates the embrittlement common in incompatible plastic blends [12].

(a)

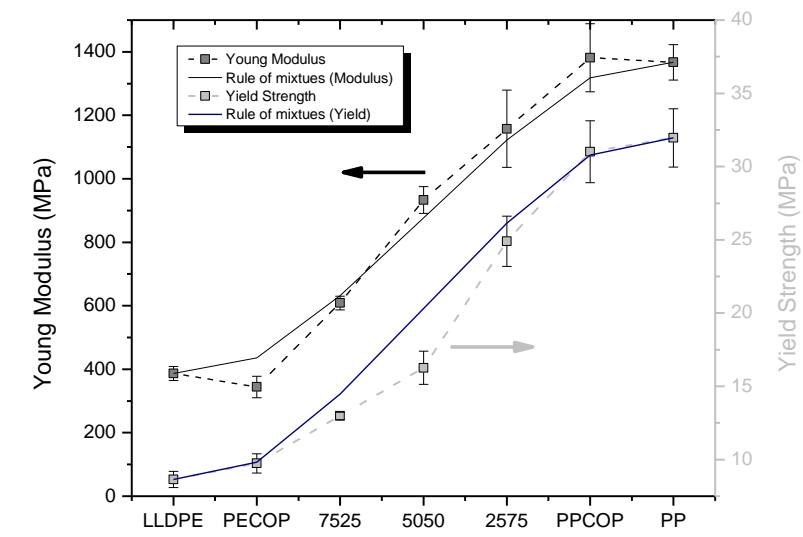

(b)

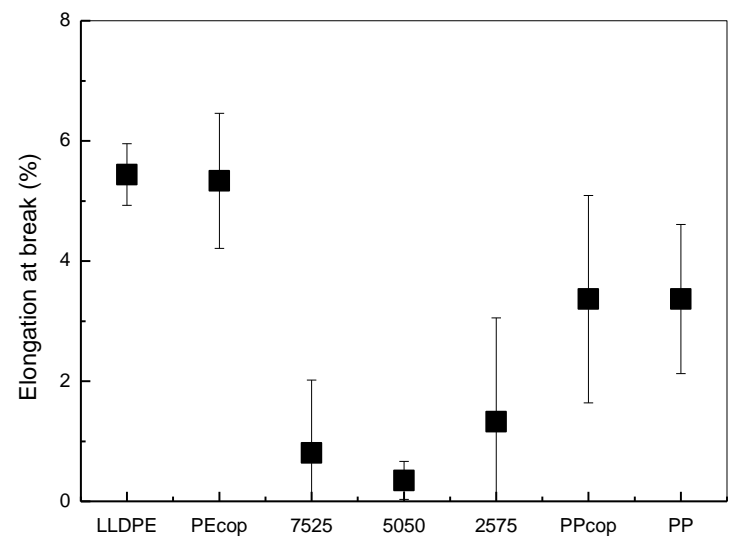

Fig. 4. Quasi-static tensile results as a function of blend's composition, (a) Yield strength and Young`s Modulus, (b) elongation at break

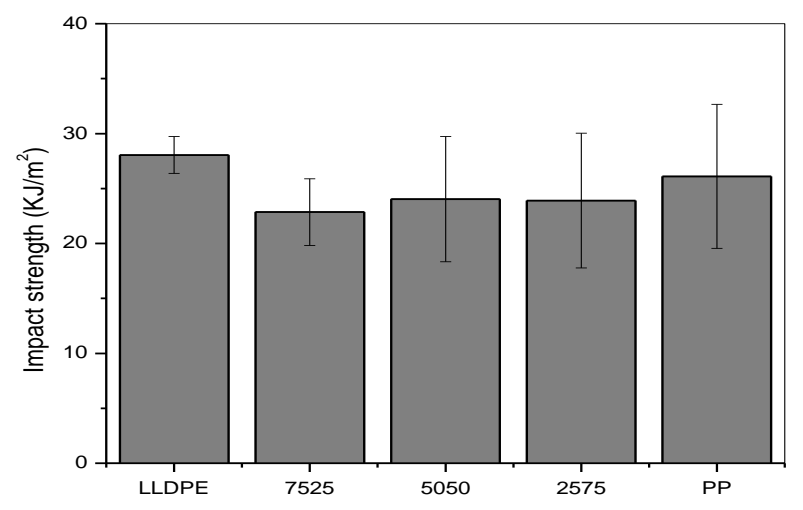

Fig. 5. Impact strength for blends.

Regarding tensile impact response, impact strength values were determined from load vs time curves and are presented in Fig. 5. Impact strength is observed to be independent of blend composition and similar to that of pure LLDPE and PP. The same trend was observed by some authors [22], but it is contrary to others' authors findings $[\mathbf{3 , 5}, \mathbf{1 2}, \mathbf{1 9}]$. They found that blend toughness is 


\section{Advanced Materials Letters www. vbripress.com/aml}

similar to that of pure PE in blends containing up to $20 \%$ of PP, but it decreases with increasing amount of PP. They attributed this behavior to both the ductile-brittle transition at 50/50 PE/PP composition and low adherence between phases. However, there is a very important difference between literature works and our work: other works are based on Izod or Charpy impact tests, while our work deals with tensile impact tests, which involves a much more severe stress environment. That is the reason why our results are not comparable with literature results. This fact is confirmed by Shan et al. [22], who evaluates impact response by means of three configurations (Izod, Charpy and biaxial falling weight) and found different tendencies for the same materials.

Even though impact strength is observed to be independent of blend composition, it is noticeable that standard deviation significantly increases with blending. This behavior can be explained by the fact that higher PP amount causes fracture mode to change from ductile to brittle starting at $50 \%$ PP, which was proved by SEM (Fig. 6), and also to the low adherence between phases.

Typical fracture surfaces as observed by SEM of impact loaded samples are shown in Fig. 6. In this figure a microscopic image and a further amplification of each material are presented to identify deformation mechanisms. In the case of LLDPE, stretching and deformation along with recovering after fracture can be seen. In 7525 blend a macroscopic plastic deformation, due to chain stretching is observed. The 5050 blend presented two behaviors: ductile and brittle, indicating that this blend is in the ductile-brittle transition regime under impact loading. This behavior is probably due to the cocontinuous morphology developed during processing in this blend. As the PP content increases, a decrease in the stretching and deformation is observed. Finally, in both 2575 and 7525 blends, the cavities observed on the fracture surface suggest that second phase droplets were easily pullout from the other phase when blends were deformed during impact $[\mathbf{1 2 , 1 9}$. Strength values remain constant although plastic deformation is greater as LLDPE content increases, revealing that LLDPE has little toughening effect on PP [19].

\section{Morphology/tensile performance relationship}

Mechanical performance of a polymer blend is mainly determined by crystallinity, morphology and interfacial properties. An increase in crystallinity would induce higher modulus with lower strain at break. In addition, when small particles are obtained, better adhesion with the matrix is achieved because of an increase in interfacial area [9]. Moreover, interfacial properties depend on the compatibilization degree and are responsible for efficient stress transfer between phases [25].

The compatibilized PP blends obtained in this work have higher modulus and yield strength than LLDPE, indicating that the addition of a small amount ( $25 \mathrm{wt} . \%)$ of PP results in a high reinforcement of LLDPE as it was a stiff filler, increasing tensile parameters in about $50 \%$. In other words, the addition of 25 wt.\% of PP has a significant effect on blends' tensile properties under quasistatic loading conditions. It seems that the PP spherulitic structure extending in all directions reinforces the $\mathrm{PE}$ phase like a fibrous filler.
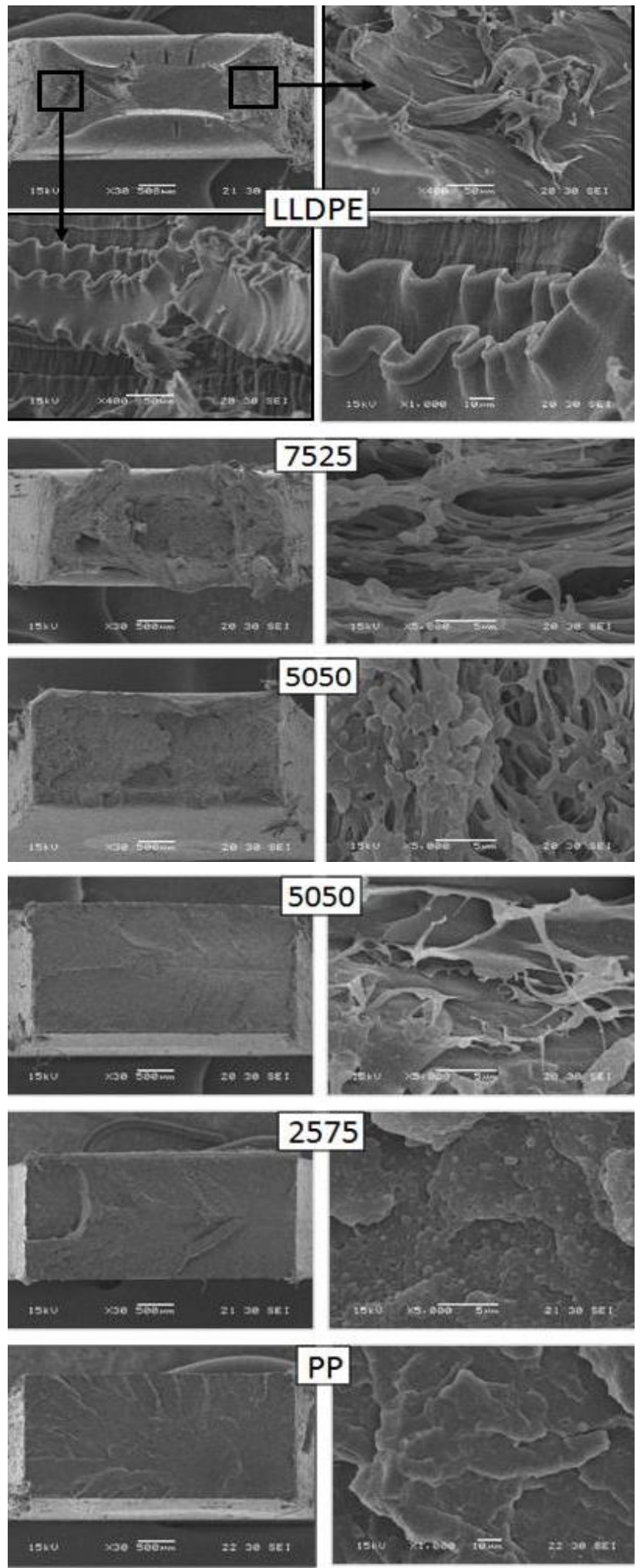

Fig. 6. Fracture surfaces of blends under impact tensile loading, as observed by SEM. 


\section{Advanced Materials Letters www. vbripress.com/aml}

The role of the adhesion between phases is also evident when analyzing the overall tensile behavior. In our blends, adhesion is enough to achieve a good load transfer at low deformation levels, but insufficient to maintain the deformation at any tensile speed, i.e. both in quasi-static and impact conditions.

Another factor that has been shown to influence tensile performance is the size of the particle inclusions. In fact, the 2575 which has smaller particles than 7525 blend, displays a slightly higher elongation at break than the other blends. Particle size is determined by processing parameters, among other factors. For example, changing the temperature profile during compounding can change the relative viscosity ratio and, therefore, the domain size and mechanical performance [12]. An advantage of adding compatibilizers is that they tend to stabilize morphology and reduce the variability of the blend's morphology. This seems to be one of the reasons why our values of mechanical properties are different from values reported by other authors $[\mathbf{1 9 , 2 5}]$.

5050 blend, with a co-continuous morphology, exhibits the lower tensile performance. At high tensile loading speed (impact tests) it is in the ductile-brittle transition regime, and at low tensile loading speed (quasi-static tests) exhibits the lower deformation at break. This is because there is a maximum in blends incompatibility when both components are present at their maximum content [6], due to coalescence phenomenon. At higher content of the dispersed phase, particles increase in size since particles recombination depends on their collision probability. If the content of the dispersed phase diminishes, particles collision probability and recombination also does [6].

\section{Conclusion}

Through this work, the tensile behavior of LLDPE/PP blends was studied. Blends present a biphasic morphology but each blend composition leads to a different microstructure, with the 5050 blend exhibiting a cocontinuous morphology with a "salami" structure. A decrease in LLDPE crystallinity degree was observed due to the obstruction generated by the already crystallized PP.

Tensile properties of the blends are significantly affected by the blend's composition. Then, different mechanical behaviors were observed, that varied from ductile to brittle under both quasi-static and dynamic loading conditions. Tensile performance was found to be directly related to the morphology of each blend.

In a next work, the blend with the most reliable behavior, 7525, will be used to obtain a ternary composite reinforced with recycled rubber particles obtained from scrap tires.

\section{Acknowledgements}

This work was supported by ANPCyT, CONICET, University of Mar del Plata, and University of Buenos Aires, from Argentina.

\section{Keywords}

Polymer blends, mechanical performance, injection molding, morphology.
Received: 19 May 2019

Revised: 18 July 2019

Accepted: 19 July 2019

\section{References}

1. Bertin S.; Robin J.J.; European Polymer Journal; 2002, 38, 2255.

2. Mourad. A-HI; Akkad, R.O.; Soliman A.A.; Madkour, T.M.; Plastics, Rubber and Composites, 2009, 38, 265.

3. Penava, N.V.; Rek, V.; Houra, I.F.; Journal of Elastomers \& Plastics, 2013, 45, 391

4. Tai, C.M.; Li RKY; Ng C.N.; Polymer Testing, 2000, 19, 143.

5. Strapasson, R.; Amico, S.C.; Pereira, M.F.R.; Sydenstricker, THD; Polymer Testing, 2005, 24, 468.

6. Jose, S.; Aprem, A.S.; Francis, B.; Chandy, M.C.; Werner, P.; Alstaedt, V.; European Polymer Journal, 2004, 40, 2105.

7. Fortelný, I.; Kruliš, Z.; Michálková, D.; Horák, Z.; Die Angewandte Makromolekulare Chemie. 1996, 238, 97.

8. Wong, AC-Y.; Lam, F.; Polymer Testing, 2002, 21, 691

9. Li, J.; Shanks, R.A.; Long, Y.; Journal of Applied Polymer Science, 2000, 76, 1151.

10. Dhoble, A.; Kulshreshtha, B.; Ramaswami, S.; Zumbrunnen, D.A.; Polymer, 2005, 46, 2244.

11. Radonjič, G.; Gubeljak, N.; Macromolecular Materials and Engineering, 2002, 287, 122.

12. Clemons C.; Composites Part A: Applied Science and Manufacturing, 2010, 41, 1559.

13. Fang, C.; Nie, L.; Liu, S.; Yu, R.; An, N.; Li, S.; Composites Part $B$ : Engineering, 2013, 55, 498.

14. Canedo, E.; Wellen, R.; Almeida, Y.; Cristalização de Polímeros Tratamento de Dados e Modelagem Macrocinética. Recife: ANP PRH-28/DEQ/UFPE; 2016

15. Wellen, RMR.; Canedo E.L.; Polymer Testing, 2015, 41, 26.

16. Ries, A.; Canedo, E. L.; Souto, C. R.; Wellen, RMR.; Thermochimica Acta, 2016, 637, 74.

17. Guimarães, Jaques N.; dos Santos, Silva ID.; Ries, A.; Canedo EL.; Ramos Wellen R.M.; J. Therm Anal Calorim., 2018, 131, 2569.

18. Sousa, F.M.; Costa, ARM.; Reul, LTA.; Cavalcanti, F.B.; Carvalho L.H.; Almeida T.G.; Polym Bull., 2019, 76, 1573.

19. Yang, M.; Wang, K.; Ye, L.; Mai, Y.W.; Wu, J.; Plastics, Rubber and Composites, 2003, 32, 27.

20. The, J.W.; Rudin, A.; Keung, J.C.; Advances in Polymer Technology, 1994, 13, 1.

21. Luciani, A.; Jarrin, J.; Polymer Engineering \& Science, 1996, 36, 1619.

22. Shan, G.F.; Yang, W.; Xie, B.H.; Yang, M.B.; Journal of Macromolecular Science, Part B, 2007, 46, 963.

23. Kallel, T.; Massardier-Nageotte, V.; Jaziri, M.; Gérard, J.F.; Elleuch, B.; Journal of Applied Polymer Science, 2003, 90, 2475.

24. Sharma, R.; Socrate, S.; Polymer, 2009, 50, 3386.

25. Tselios, C.; Bikiaris, D.; Maslis, V.; Panayiotou, C.; Polymer, 1998, 39, 6807

26. Costantino, M.A.; Pettarin, V.; Pontes, A.; Frontini, P.; Express Polymer Letters, 2015, 9, 1040

27. Borovanska, I.; Dobreva, T.; Benavente, R.; Djoumaliisky, S.; Kotzev, G.; Journal of Elastomers \& Plastics, 2012, 44, 479.

28. Jin, M.; Jin, B.; Xu, X.; Li, X.; Wang, T.; Zhang, J.; Polymer Testing, 2015, 46, 41

29. Wu, T.; Li, Y.; Wu, G.; Polymer, 2005, 46, 3472. 